\title{
Armazenamento de sementes de xique-xique ${ }^{1}$
}

\author{
Haynna Fernandes Abud ${ }^{2 *}$, Diego de Sousa Pereira ${ }^{3}$, Nayara Roberto Gonçalves ${ }^{2}$, \\ Magnum de Sousa Pereira ${ }^{4}$, Antonio Marcos Esmeraldo Bezerra ${ }^{4}$
}

\begin{abstract}
RESUMO - Objetivou-se avaliar a qualidade fisiológica de sementes de xique-xique (Pilosocereus gounellei) armazenadas em diferentes ambientes e embalagens durante o período de seis meses. Utilizou-se o delineamento inteiramente casualizado com quatro repetições, num esquema de parcelas subdivididas. As parcelas receberam a combinação de dois ambientes de armazenamento, câmara fria e ambiente natural, e três embalagens, saco de papel multifoliado, saco de plástico e vidro. As subparcelas constaram dos períodos de armazenamento 0, 2, 4 e 6 meses. Após cada período de armazenamento, avaliou-se o teor de água, a porcentagem, o índice de velocidade e tempo médio de germinação. A câmara fria é mais adequada ao armazenamento de sementes de xique-xique quando comparada ao ambiente natural. Neste ambiente, todas as embalagens testadas foram eficientes em manter a qualidade fisiológica. Em ambiente natural, as sementes acondicionadas em saco de plástico apresentaram a maior germinação (87\%), porém o saco de papel multifoliado mostrou-se mais estável em todas as variáveis analisadas, com germinação de $58 \%$, velocidade de 3,9 e tempo médio de germinação de 7,9 dias ao final de seis meses de armazenamento. Em ambiente natural, o saco de papel multifoliado, é a condição ideal para a conservação da viabilidade de sementes de xique-xique.
\end{abstract}

Termos para indexação: Pilosocereus gounellei, germinação, potencial fisiológico, vigor.

\section{Storage of xique-xique seeds}

\begin{abstract}
The objective of this study was to evaluate the physiological quality of Pilosocereus gounellei seeds stored in different environments and types of packaging for six months. The experimental design was completely randomized, in split plots with four replications. The plots received two storage environments, cold chamber and natural environment, and three types of package, multi-layer paper bag, plastic bag and glass. The subplots received the storage periods 0, 2, 4 and 6 months. After each storage period, the seed moisture content, percentage of germination, germination speed index and mean time of germination were evaluated. The cold chamber was more suitable to store xique-xique seeds compared to the natural environment. In that environment, all the packages were effective to keep the physiological quality. In the natural environment, the seeds packed in plastic bags showed the highest percentage of germination (87\%), but the multi-layer paper bag was more stable for all variables, with $58 \%$ of germination, speed index of germination equals to 3.9 and mean time of germination of 7.9 days after six months of storage. In the natural environment, multi-layer paper bags showed the best results to the conservation of xique-xique seed viability.
\end{abstract}

Index terms: Pilosocereus gounellei, germination, physiological potential, vigor.

${ }^{1}$ Submetido em 21/04/2011. Aceito para publicação em 01/09/2011.

${ }^{2}$ Departamento de Fitotecnia, Universidade Federal de Viçosa, 36570-000-Viçosa, MG, Brasil.
${ }^{4}$ Departamento de Fitotecnia, Universidade Federal do Ceará, 60356-000-Fortaleza, CE, Brasil.

*Autor para correspondência <hfabud@gmail.com>

${ }^{3}$ Departamento de Agricultura, Universidade Federal de Lavras, Caixa Postal 37, 37200-000-Lavras, MG, Brasil. 


\section{Introdução}

O armazenamento das sementes em condições adequadas de temperatura e umidade relativa do ar favorece a manutenção do seu potencial fisiológico, reduzindo o processo respiratório e diminuindo, desta forma, o processo de deterioração das mesmas (Marcos-Filho, 2005; Carvalho e Nakagawa, 2000). Segundo Merrit et al. (2003), o conhecimento sobre a relação existente entre a temperatura de armazenamento, a umidade relativa do ar ambiente e o teor de água da semente é imprescindível para o desenvolvimento de protocolos de armazenamento de sementes.

Os efeitos das condições ambientais de temperatura e umidade relativa do ar sobre o desempenho de sementes, durante o armazenamento, dependem das características das espécies. Isto se deve ao fato de que, dentre outros fatores, semente de diferentes espécies apresentam diferentes constituições químicas, com distintos componentes de reserva sintetizados e acumulados durante o processo de formação, tais como proteínas, carboidratos, especialmente o amido e lipídeos (Graham, 2008).

As sementes que contém elevado teor de óleo apresentam menor potencial de armazenamento quando comparadas aquelas que possuem reservas amiláceas, devido à menor estabilidade química dos lipídios em relação ao amido (Taiz e Zeiger, 2009; Nery et al. 2007). Segundo Graham (2008), os principais responsáveis, no nível celular, pela redução na viabilidade das sementes são o aumento na peroxidação de lipídeos, a deterioração das membranas, o aumento de radicais livres e a redução da atividade de enzimas específicas. Nobel (2002) afirma que as sementes de muitas espécies selvagens de cactáceas possuem elevado conteúdo de lipídeos e apresentam uma testa fina, com a presença de grânulos de amido, o que favorece o processo de germinação.

Mesmo com o aumento das pesquisas, ainda são escassas as informações sobre o comportamento fisiológico das sementes de cactos após longos períodos de armazenamento, seja sob condições controladas, como em bancos de sementes no solo (Godínez - Alvarez, 2003). Andrade et al. (2005) avaliaram diferentes condições de armazenamento, ambiente natural, câmara seca $\left(16-18{ }^{\circ} \mathrm{C}\right.$ e $60 \%$ UR) e câmara fria $\left(10^{\circ} \mathrm{C}\right.$ e $70 \%$ UR $)$ de sementes de pitaya vermelha (Hylocereus undatus), e constataram que câmara fria foi a melhor condição para a manutenção da qualidade fisiológica das sementes desta espécie. FloresMartínez et al. (2008) avaliaram a idade de germinação de sementes de Mammillaria huitzilopochtli, sob condições controladas e naturais e verificaram que a germinação das sementes decresceu com o tempo, o que indica que esta espécie pode ser capaz de formar um banco de sementes temporário no solo, de aproximadamente um ano. VeigaBarbosa et al. (2010) observaram que a criopreservação pode fornecer um método útil de armazenamento a longo prazo de sementes de cactáceas, do nordeste do Brasil.

Estudos relacionados à germinação e viabilidade de sementes de cactáceas nativas da região Nordeste ainda são escassos, e poucos resultados são encontrados na literatura, tais como aqueles realizados com as espécies Stenocereus stellatus (Rojas-Aréchiga et al. 2001), Stenocereus queretaroensis (Barrera e Nobel, 2003), Stenocereus queretaroensis (LozaCornejo et al. 2003), Hylocereus setaceus (Simão et al. 2007), Denmoza rhodacantha (Mendéz, 2007), Trichocereus terscheckii (Ortega-Baes e Rojas-Aréchiga, 2007), Melocactus bahiensis (Lone et al. 2007), Cereus fernambucensis, Coleocephalocereus fluminensis, Pilosocereus arrabidae e Pilosocereus ulei (Almeida et al., 2009), Pilosocereus pachycladus (Abud et al., 2010), dentre outros.

Diante do exposto, o objetivo do presente trabalho foi avaliar a qualidade fisiológica de sementes de xique-xique armazenadas em dois ambientes e três embalagens.

\section{Material e Métodos}

As sementes de xique-xique utilizadas no experimento foram oriundas de frutos maduros, colhidos de exemplares existentes na Fazenda Experimental Vale do Curu, da Universidade Federal do Ceará, localizada em PentecosteCE. Após a colheita, os frutos foram acondicionados em sacos plásticos e transportados para o Laboratório de Análises de Sementes (UFC), onde o experimento foi conduzido, no período de abril a outubro de 2009. Utilizou-se o delineamento inteiramente casualizado, com quatro repetições, em esquema de parcelas subdivididas. Nas parcelas, foram casualizadas as combinações de dois ambientes de armazenamento e três tipos de embalagens. Os ambientes foram câmara fria, com temperatura de $10{ }^{\circ} \mathrm{C}$ e umidade relativa de $60 \%$ e, ambiente natural com temperatura de $26,6{ }^{\circ} \mathrm{C}$ e umidade relativa de $76,9 \%$. Utilizou-se embalagem impermeável de vidro, embalagem semipermeável de saco de plástico, e embalagem permeável de saco de papel multifoliado. Enquanto nas subparcelas constaram os períodos de armazenamento $(0,2,4$ e 6 meses). Cada unidade experimental recebeu $5 \mathrm{~g}$ de sementes de xique-xique.

Os dados meteorológicos referentes à temperatura $\mathrm{e}$ umidade relativa do ar durante o período experimental, 
foram fornecidos pela Estação Meteorológica da Universidade Federal do Ceará, no Campus do Pici (Figura 1).

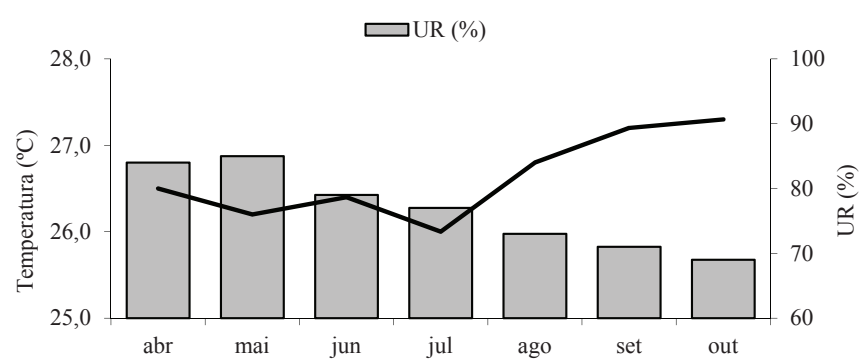

Figura 1. Médias mensais de temperatura $\left({ }^{\circ} \mathrm{C}\right)$ e umidade relativa do ar (\%) registradas em Fortaleza (CE), no período de abril a outubro de 2009.

Para determinação do teor de água das sementes foi utilizado o método de estufa a $105 \pm 3{ }^{\circ} \mathrm{C}$ por 24 horas, de acordo com as Regras para Análise de Sementes (Brasil, 2009).

Para a avaliação da germinação, as sementes foram semeadas em placas de Petri, sobre duas folhas de papel de filtro, umedecidas com água destilada na proporção de 2,5 vezes o peso do papel. Foram consideradas germinadas as sementes que originaram plântulas com radícula de comprimento igual ou maior que um milímetro (Brasil, 2009). As placas foram acondicionadas em germinadores tipo BOD regulados a temperatura constante de $25^{\circ} \mathrm{C}$, sob fotoperíodo de 16 horas de escuro e 8 horas de luz. Para verificar o efeito dos tratamentos foram realizadas contagens diárias a partir da protrusão da radícula da primeira plântula, até o $16^{\circ}$ dia após a semeadura. Foram avaliadas a porcentagem de germinação, computando-se as plântulas normais na última contagem, com os resultados foram expressos em porcentagem; o índice de velocidade de germinação, calculado a partir de contagens diárias, conforme metodologia proposta por Maguire (1962); o tempo médio de germinação, calculado a partir das contagens diárias, de acordo com o modelo proposto por Labouriau (1983), sendo os resultados expressos em número de dias após a semeadura. As variáveis foram submetidas à análise de variância e os resultados submetidos à análise de regressão polinomial, conforme (Banzatto e Kronka, 2006).

\section{Resultados e Discussão}

Os teores de água das sementes de xique-xique determinados durante $\mathrm{o}$ armazenamento por seis meses, nas embalagens e ambientes testados, situou-se entre 7 e $12 \%$ (Tabela 1). Marcos-Filho (2005) afirma que de modo geral, o teor de água das sementes ortodoxas deve ser mantido de 10 a $12 \%$ para o armazenamento durante seis a oito meses, sendo os valores mais baixos indicados para espécies em que predominam reservas lipídicas. Nobel (2002) cita que as sementes de muitas espécies selvagens de cactáceas possuem elevado conteúdo de lipídeos.

Tabela 1. Teor de água (\%) de sementes de xique-xique acondicionadas em três embalagens e armazenadas em dois ambientes no período de seis meses.

\begin{tabular}{ccrrrr}
\hline \multirow{2}{*}{ Ambiente } & Embalagem & \multicolumn{4}{c}{ Meses } \\
\cline { 3 - 6 } & & 0 & 2 & \multicolumn{1}{c}{4} & 6 \\
\hline \multirow{2}{*}{ Câmara fria } & Papel & 10,2 & 9,9 & 9,4 & 9,3 \\
& Plástico & 9,6 & 8,9 & 9,9 & 10,2 \\
& Vidro & 11,1 & 9,1 & 9,4 & 7,2 \\
Ambiente natural & Papel & 9,7 & 10,5 & 7,5 & 8,2 \\
& Plástico & 10,3 & 8,4 & 11,6 & 8,1 \\
& Vidro & 9,5 & 9,1 & 7,0 & 8,8 \\
\hline
\end{tabular}

Observa-se que as sementes armazenadas em câmara fria apresentaram pequenas variações nos teores de água iniciais das sementes, com médias de 9,7; 9,7 e 9,2\% para papel, plástico e vidro, respectivamente, sugerindo que a troca de vapor entre as sementes e o ambiente foi mínima, pois a umidade relativa do ar na câmara fria manteve-se constante, com $60 \%$, durante todo o período de armazenamento (Tabela 1). A conservação das sementes é favorecida em câmara fria, pois este ambiente possibilita o controle da temperatura e umidade relativa do ar, reduzindo desta forma a deterioração dos compostos de reserva. Já os teores de água de sementes de xique-xique sob condições de ambiente natural situaram-se em torno de 9,0; 9,6 e 8,6\% nas embalagens saco de papel multifoliado, saco de plástico e vidro, respectivamente (Tabela 1). A conservação do potencial fisiológico das sementes depende, em grande parte, do seu grau de umidade inicial e das condições do 
ambiente de armazenamento (Marcos- Filho, 2005). O teor de água das sementes sofre flutuações com a umidade relativa do ar, por meio da troca de vapor d'água entre as sementes e o ambiente, uma vez que estas apresentam uma elevada capacidade higroscópica. Na Figura 1 pode-se verificar que nas condições naturais de Fortaleza, durante o período experimental, a temperatura variou de $26{ }^{\circ} \mathrm{C}$ a $27,3{ }^{\circ} \mathrm{C}$, com média de $26,6{ }^{\circ} \mathrm{C}$ e a umidade relativa do ar apresentou variação de 69 a $84 \%$. De acordo com a Tabela 1 verifica-se que o teor de água das sementes de xiquexique apresentou uma reduzida variação com as mudanças de temperatura e umidade relativa do ar, durante o período do experimento.

$\mathrm{Na}$ Figura 2 estão apresentados os resultados de porcentagem de germinação das sementes de xique-xique acondicionadas nas três embalagens e dois ambientes, por um período de seis meses. Para as sementes armazenadas em câmara fria observou-se que, nas embalagens saco de papel multifoliado e saco plástico, a germinação das sementes manteve-se constante e acima de $90 \%$, durante o período de armazenamento. Para embalagem impermeável, vidro, observou-se que logo no segundo mês de armazenamento já houve redução na germinação das sementes, porém essa diminuição não foi tão acentuada, sendo ao final do experimento obtido o valor de $89 \%$ (Figura $2 \mathrm{~A}$ ).

Em ambiente natural, observou-se comportamento linear da germinação das sementes armazenadas em sacos de papel multifoliado e sacos plásticos, com taxas decrescentes de 5,87 e 1,62\% ao mês, respectivamente. Pode-se verificar que a embalagem saco plástico proporcionou a melhor conservação da qualidade das sementes de xique-xique, com maior valor de germinação ao final do período de armazenamento, ou seja, $87 \%$. Na embalagem em impermeável vidro, o comportamento fisiológico das sementes apresentou comportamento cúbico, onde logo no segundo mês de armazenamento observou-se elevada redução da porcentagem de germinação, a qual era inicialmente $67 \%$, chegando a apenas $12,5 \%$ ao final do período de armazenamento (Figura 2B).

Estes resultados mostram que a câmara fria é $\mathrm{O}$ ambiente mais adequado para a conservação das sementes desta espécie quando comparado ao ambiente natural, proporcionando maiores porcentagens de germinação. Este comportamento é esperado, e se deve ao fato de que em câmara fria é possível o controle da temperatura, mantendo-a baixa e constante. Baixas temperaturas reduzem a velocidade das reações químicas, consequentemente a respiração, beneficiando a conservação das sementes (Marcos-
Filho, 2005). Graham (2008) cita que a deterioração das sementes altera significativamente os processos bioquímicos e fisiológicos das sementes, aumentando a degradação dos compostos de reserva, reduzindo a porcentagem de germinação das sementes estocadas em condições inadequadas à sua conservação, pois durante o processo de deterioração ocorre a produção de espécies reativas de oxigênio, que alteram a estrutura de enzimas antioxidantes, ocasionando uma diminuição mais acentuada na viabilidade das sementes.
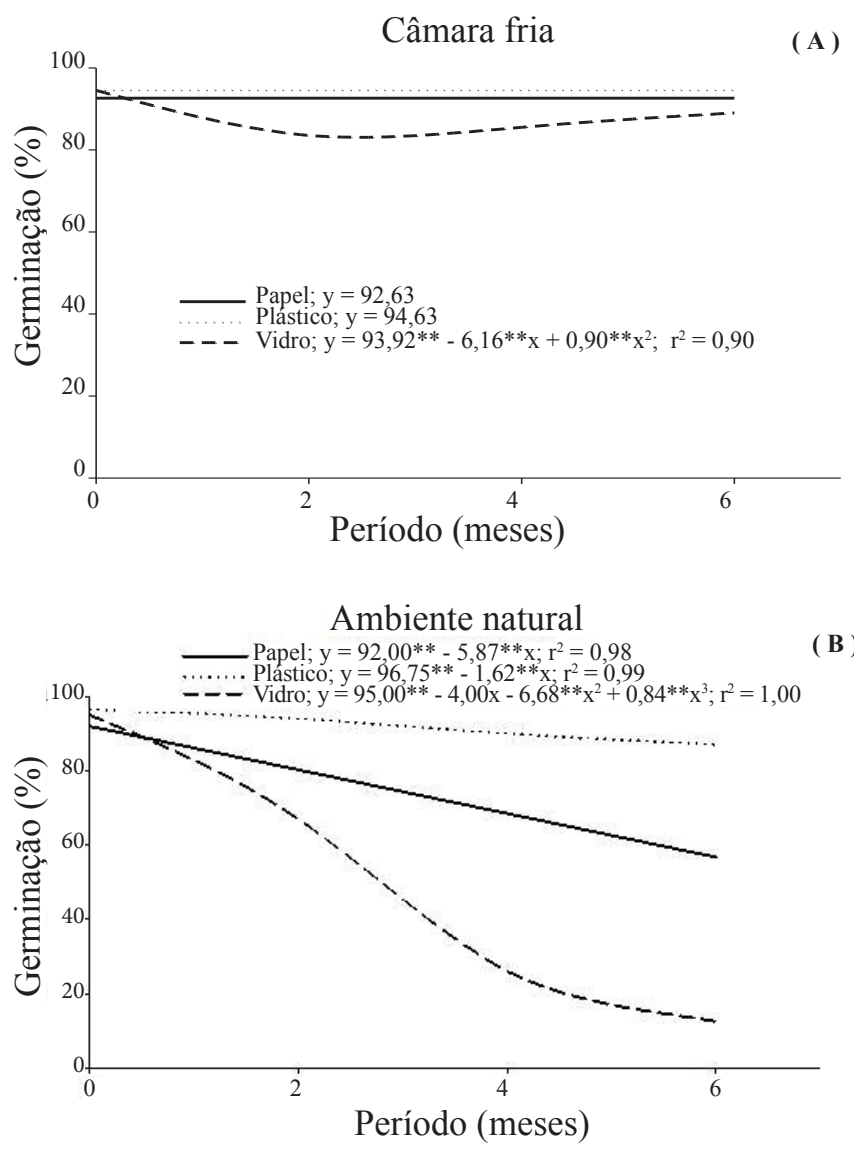

Figura 2. Porcentagem de germinação de sementes de xiquexique, acondicionadas em três embalagens e armazenadas em dois ambientes (A e B), durante seis meses.

Andrade et al. (2005), em estudo semelhante avaliando os efeitos das condições de armazenamento sobre a germinação de Pitaya vermelha (Hylocereus undatus), verificaram que as condições de câmara fria são ideais para a conservação das sementes quando comparadas as de ambiente natural e câmara seca.

Com relação à velocidade de germinação das sementes, observa-se que para as sementes de xique- 
xique armazenadas em câmara fria (Figura 3A) observouse comportamento quadrático quando armazenadas em embalagens sacos de papel multifoliado e vidros, enquanto que para sacos plásticos a velocidade oscilou em torno de 7.4, durante todo o período de armazenamento. Observase que para as três embalagens testadas nestas condições a velocidade de germinação foi elevada até o final do experimento, com índices superiores a 7,0 (Figura 3A). Este resultado sugere que a câmara fria é o ambiente mais adequado para o armazenamento durante um período de seis meses, favorecendo a manutenção a qualidade fisiológica das sementes, observada por meio da avaliação da porcentagem de germinação (Figura 2A) e índice de velocidade de germinação (Figura 3A).
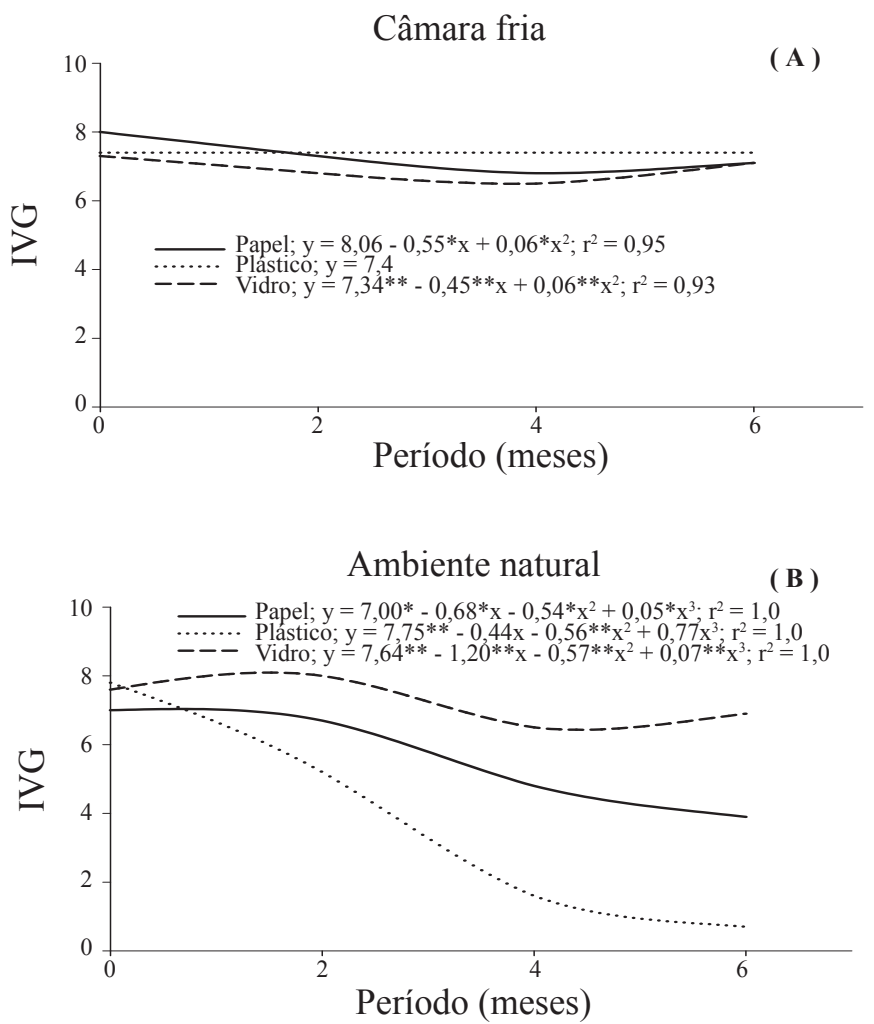

Figura 3. Índice de velocidade de germinação (IVG) de sementes de xique-xique, acondicionadas em três embalagens e armazenadas em dois ambientes (A e B), durante seis meses.

Em ambiente natural (Figura 3B), verificou-se uma perda de vigor mais acentuada em todas as embalagens testadas comparado aos resultados do armazenamento em câmara fria. Constatou-se que a embalagem vidro proporcionou menores flutuações da qualidade fisiológica durante o período de armazenamento, com velocidade de germinação inicial de 7.6 e final de 6.9. No entanto, nesta embalagem as sementes obtiveram os menores valores de germinação após seis meses de armazenamento (Figura 2B). Maiores reduções na velocidade de germinação foram observadas nas sementes acondicionadas em saco plástico, tendo estas, obtido ao final do período de armazenamento um índice de 0,7. Para as sementes acondicionadas em sacos de papel verificou-se uma maior redução na velocidade, atingindo índice de 3,9 aos seis meses de armazenamento, tendo apresentado, no entanto, comportamento intermediário quando comparado as demais embalagens avaliadas.

Segundo Marcos-Filho (2005) a baixa velocidade de germinação é um dos indicativos de menor potencial fisiológico, sendo uma das manifestações mais evidentes do processo de deterioração.

Examinando-se o comportamento das sementes de xique-xique durante o armazenamento em câmara fria, pode-se observar que as embalagens saco plástico e vidro proporcionaram tempos médios de germinação em média de 6,7 dias. Enquanto que a embalagem saco de papel multifoliado proporcionou comportamento linear, apresentando taxas crescentes de 0,12 dias ao mês. Pode-se observar que não houve grandes variações quanto ao tempo médio de germinação entre as três embalagens estudadas, constatando-se que durante todo o período de armazenamento o tempo médio cituou-se abaixo de 7,0 dias (Figura 4A).

Em ambiente natural observou-se comportamento linear, quadrático e cúbico dos resultados da variável tempo médio de germinação para as sementes acondicionadas em saco plástico, saco de papel multifoliado e vidro, respectivamente. Na Figura 4B, verifica-se que a embalagem vidro proporcionou $\mathrm{O}$ menor tempo médio de germinação, com 6,6 dias, seguido da embalagem saco de papel multifoliado, com 7,9 dias. O maior tempo de germinação foi verificado para as sementes armazenadas em embalagem saco plástico, as quais, ao final do período de armazenamento, apresentaram uma média de 9,4 dias, com uma taxa crescente de 0,53 dias ao mês.

Para as sementes de xique-xique verificou-se que a embalagem semipermeável, saco plástico, apresentou a maior porcentagem de germinação, com 87\% (Figura 2B). Porém o saco de papel multifoliado mostrou-se mais estável em todas as variáveis analisadas, com germinação de 58\% (Figura 2B), velocidade de 3,9 (Figura 3B) e tempo médio de germinação de 7,9 dias (Figura 4B) ao final de seis meses de armazenamento. 

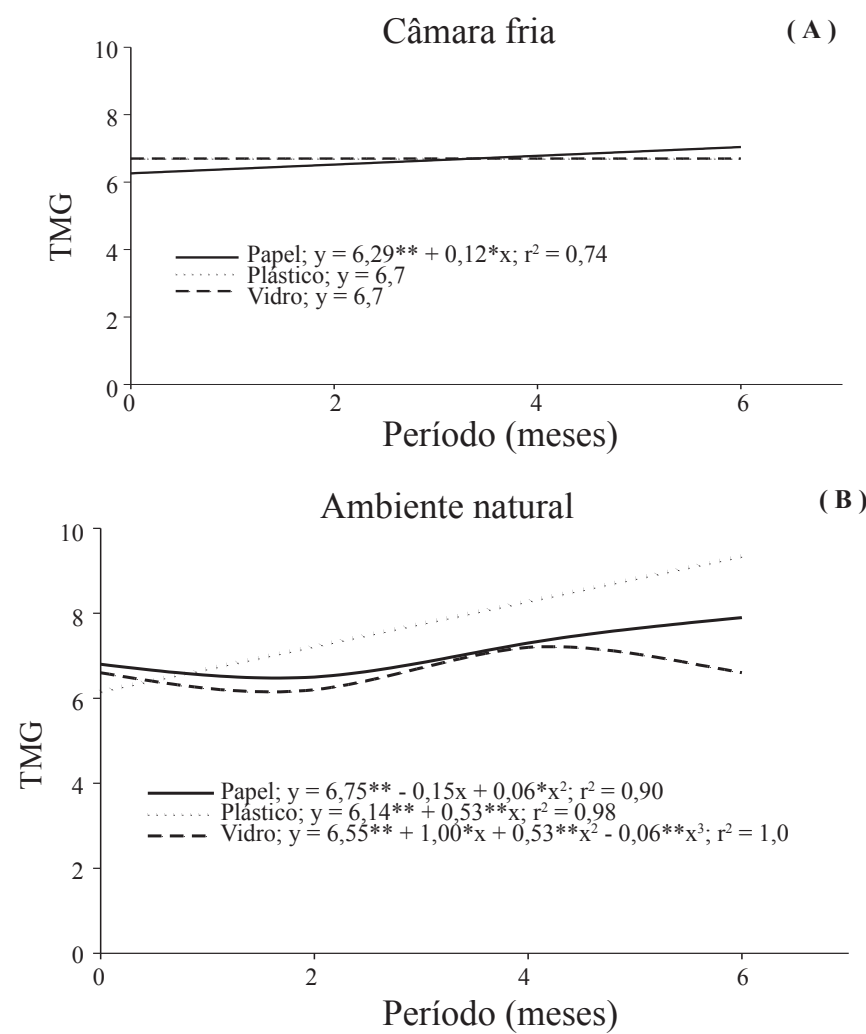

Figura 4. Tempo médio de germinação (TMG) de sementes xique-xique, acondicionadas em três embalagens e armazenadas em dois ambientes (A e B), durante seis meses.

Andrade et al. (2005) observaram que o tempo médio de germinação aumentou consideravelmente com o período de armazenamento em sementes de pitaya vermelha (Hylocereus undatus). Os autores observaram que a germinação das sementes após um período de armazenamento de sete dias era iniciada aproximadamente aos 14 dias após a semeadura. Quando as sementes eram armazenadas por 28 dias a germinação iniciou-se por volta de 35 dias após a semeadura. Este comportamento foi observado pelos autores em todos os ambientes estudados.

\section{Conclusões}

A câmara fria é o ambiente mais apropriado para o armazenamento de sementes de xique-xique por seis meses, sendo as embalagens saco de papel multifoliado, saco plástico e vidro eficientes na manutenção da qualidade fisiológica das sementes.

Em ambiente natural, a utilização da embalagem permeável saco de papel multifoliado é a condição de armazenamento ideal para a conservação da viabilidade de sementes de xique-xique, seis meses.

\section{Referências}

ABUD, H.F.; GONÇALVES, N.R.; REIS, R.G.E.; PEREIRA, D.S.; BEZERRA, A.M.E. Germinação e expressão morfológica de frutos, sementes e plântulas de Pilosocereus pachycladus Ritter. Revista Ciência Agronomica, v.41, n.3, p.468-474, 2010. http://www.scielo.br/pdf/rca/ v41n3/v41n3a21.pdf

ALMEIDA, T.M.H.; ANDRADE, A.C.S.; LOPES, H.M. Brazilian cacti seed germination under different temperature and substrate conditions. Seed Science and Technology, v.37, p.474-479, 2009. http://www. ingentaconnect.com/content/ista/sst/2009/00000037/00000002/art00021

ANDRADE, R.A.; OLIVEIRA, I.V.M.; MARTINS, A.B.G. Influência da condição e período de armazenamento na germinação de sementes de Pitaya vermelha. Revista Brasileira de Fruticultura, v. 27, n.1, p.168170, 2005. http://www.scielo.br/pdf/rbf/v27n1/24593.pdf

BARRERA, E.D.; NOBEL, P.S. Physiological ecology of seed germination for the columnar cactus Stenocereus queretaroensis. Journal of Arid Enviroments, v.53, p.297-306, 2003. http://www.sciencedirect. com/science/article/pii/S0140196302910505

BANZATTO, D.A.; KRONKA, S.N. Experimentação agrícola. 4.ed. Jaboticabal: FUNEP, 2006. 237p.

BRASIL. Ministério da Agricultura, Pecuária eAbastecimento. Regras para análise de sementes. Ministério da Agricultura, Pecuária e Abastecimento. Secretaria de Defesa Agropecuária. Brasília: MAPA/ACS, 2009. 395p. http://www.agricultura.gov.br/arq_editor/file/Laborat\%C3\%B3rio/ Sementes/Regras\%20para\%20Analise\%20de\%20Sementes.pdf

CARVALHO, N.M.; NAKAGAWA, J. Sementes: ciência, tecnologia e produção. 4.ed. Jaboticabal: FUNEP, 588p. 2000.

FLORES-MARTÍNEZ, A.; MANZARENO, G.I.; ROJAS-ARÉCHIGA, M.; MANDUJANO, M.C.; GOLUBOV, J. Seed age germination responses and seedling survival of an endangered cactus that inhabits cliffs. Natural Areas Journal, v.28, p.51-57, 2008. http://www.bioone. org/doi/abs/10.3375/0885-8608\%282008\%2928\%5B51\%3asagras $\% 5 \mathrm{~d} 2$ $.0 . \mathrm{co} \% 3 \mathrm{~b} 2$

GODÍNEZ-ÁLVAREZ, H. Demographic trends in the Cactaceae. The Botanical Review, v.69, n.2, p.173-203, 2003. http://www.springerlink. com/content/d423255u2080133k/

GRAHAM, I.A. Seed storage oil mobilization. Annual Review of Plant Biology, v.59, p.115-142, 2008. http://www.annualreviews.org/doi/ pdf/10.1146/annurev.arplant.59.032607.092938

LABOURIAU, L.G. A germinação das sementes. Washington, D.C.: Secretaria Geral da OEA, 1983. 147p. 
LONE, A.B.; TAKAHASHI, L.S.A.; FARIA, R.T.; UNEMOTO, L.K. Germinação de Melocactus bahiensis (Cactaceae) em diferentes substratos e temperaturas. Scientia Agraria, v.8, p.365-369, 2007. http:// ojs.c3sl.ufpr.br/ojs2/index.php/agraria/article/view/9881

LOZA-CORNEJO, S.; TERRAZAS, T.; LOPEZ-MATA, L.; TREJO, C. Características morfo-anatómicas y metabolismo fotosintético en plántulas de Stenocereus queretaroensis (Cactaceae): su significado adaptativo. Interciência, v.28, p.83-89, 2003. http://redalyc.uaemex.mx/ redalyc/src/inicio/ArtPdfRed.jsp?iCve=33907704

MAGUIRE, J.D. Speed of germination-aid in selection and evaluation for seedling emergence and vigor. Crop Science, v.2, n.1, p.176-177, 1962.

MARCOS-FILHO, J. Fisiologia de sementes de plantas cultivadas. Piracicaba: FEALQ, 2005. 495p.

MÉNDEZ, E. Germination of Demonza rhodacantha (Salm-Dyck) Britton \& Rose (Cactaceae). Journal of Arid Environments, v.68, p.678-682, 2007. http://www.scielo.br/scielo.php?script=sci nlinks\&ref $=000090 \&$ pid $=$ S1806-6690201000030002100017\&lng=en

MERRIT, D.J.; TOUCHELF, D.H.; SENARATNA, T.; DIXON, K.W.; SIVASITHAMPARAM, K. Water sorption characteristics of seeds of four western Australin species. Australian Journal of Botany, v.53, p.8592, 2003. http://www.publish.csiro.au/paper/BT02040.htm

NERY, F.C.; ALVARENGA, A.A.; JUSTO, C.F.; CASTRO, E.M.; STEIN, V.C. Caracterização morfológica e química de sementes de Calophyllum brasiliense Cambess. Revista Brasileira de Biociências, v.5, n.2, p.144-146, 2007. http://www6.ufrgs.br/seerbio/ojs/index.php/ rbb/article/view/162/156
NOBEL, P.S. Cactus: biology and uses. University of California Press, California. 304 p. 2002.

ORTEGA-BAES, P.; ROJAS-ARÉCHIGA, M. Seed germination of Tricocereus terscheckii (Cactaceae): Light, temperature and giberellinic acid effects. Journal of Arid Environments, v.69, p.169 -176, 2007. http:// www.sciencedirect.com/science/article/pii/S0140196306002710

ROJAS-ARÉCHIGA, M.; CASAS, A.; VÁZQUEZ-YANES, C. Seed germination of wild and cultivated Stenocereus stellatus (Cactaceae) from the Tehuacán-Cuicatlán Valley, Central México. Journal of Arid Environments, v.49, p.279-287, 2001. http://www.sciencedirect.com/ science/article/pii/S014019630190789X

SIMÃO, E.; SOCOLOWSKI, F.; TAKAKI, M. The epiphytic Cactaceae Hylocereus setaceus (Salm-Dick ex DC.) ralf bauer seed germination is controlled by light and temperature. Brazilian Archives of Biology and Technology, v.50, p.655-662, 2007. http://www.scielo.br/pdf/babt/ v50n4/11.pdf

TAIZ, L.; ZEIGER, E. Fisiologia vegetal. 4.ed. Porto Alegre: Artmed, 848p. 2009.

VEIGA-BARBOSA, L.; GONZÁLEZ-BENITO, M.E.; ASSIS, J.G.A.; PÉREZ-GARCÍA, F. Germination and cryopreservation of several cactus species from NE Brazil. Seed Science and Technology, v.38, p.218-224, 2010. http://www.ingentaconnect.com/content/ista/ sst/2010/00000038/00000001/art00022 